\title{
Aerobic fitness of children and adolescents
}

\author{
Neil Armstrong*
}

\begin{abstract}
Aerobic fitness may be defined as the ability to deliver oxygen to the muscles and to utilize it to generate energy during exercise. Aerobic fitness therefore depends upon the pulmonary, cardiovascular and haematological components of oxygen delivery and the oxidative mechanisms of the exercising muscle. Maximal oxygen uptake $\left(\mathrm{VO}_{2 \text { max }}\right)$, the highest rate at
\end{abstract} which an individual can consume oxygen during exercise, is widely recognized as the best single measure of aerobic fitness. ${ }^{1}$ However, although $\mathrm{VO}_{2 \max }$ limits the performance of aerobic exercise it does not describe fully all aspects of aerobic fitness. Exercise of the intensity and duration required to elicit $\mathrm{VO}_{2 \text { max }}$ is rarely experienced by many young people and typical bouts of physical activity are submaximal and of short duration. ${ }^{2}$ Under these circumstances, it is the transient kinetics of $\mathrm{VO}_{2}$ which best assesses the integrated response of the oxygen delivery system and the metabolic requirements of the exercising muscle. The time constant of the young person's $\mathrm{VO}_{2}$ kinetic response to exercise is not related to $\mathrm{VO}_{2 \max } \cdot{ }^{3}$ Furthermore, $\mathrm{VO}_{2 \max }$ is neither the best measure of the ability to sustain submaximal exercise nor the most sensitive means of monitoring improvements in aerobic fitness with training. Despite its origins in anaerobic metabolism, blood lactate accumulation provides a valuable indicator of submaximal aerobic fitness and a means of detecting improvements in muscle oxidative capacity with training in the absence of changes in $\mathrm{VO}_{2 \max } \cdot{ }^{3} \mathrm{VO}_{2 \text { max }}$ is, however, the most widely documented measure of young people's aerobic fitness and I will focus on this variable.

Robinson ${ }^{4}$ published the first laboratory study of boys' $\mathrm{VO}_{2 \max }$ in 1938 and Astrand $^{5}$ reported the $\mathrm{VO}_{2 \max }$ of both boys and girls in 1952, yet the assessment and interpretation of young people's $\mathrm{VO}_{2 \max }$ is still shrouded

\footnotetext{
* Professor, University of Exeter, Exeter, UK. Director, Children's Health and Exercise Research Centre, University of Exeter, Exeter, UK.

Suggested citation: Armstrong N. Aerobic fitness of children and adolescents. J Pediatr (Rio J). 2006;82:406-8.

doi:10.2223/JPED.1571
}

with controversy. The conventional criterion for the attainment of $\mathrm{VO}_{2 \max }$ during an exercise test is a levelling-off or plateau in $\mathrm{VO}_{2}$ despite an increase in exercise intensity, but over 50 years ago Astrand 5 demonstrated that this response is not typical of the majority of children and adolescents. It has therefore become more common to use the term peak $\mathrm{VO}_{2}$, the highest $\mathrm{VO}_{2}$ elicited during a progressive exercise test to exhaustion, to describe young people's aerobic fitness. If in a progressive exercise test the young participant exhibits clear symptoms of fatigue, supported by a heart rate which is levelling off at about 200 beats. $\mathrm{min}^{-1}$ and a respiratory exchange ratio $>1.0$, a maximal effort can be assumed and peak $\mathrm{VO}_{2}$ has been shown to reflect the limits of aerobic fitness. ${ }^{6}$ Peak $\mathrm{VO}_{2}$ is a robust variable with a repeatability across three trials a week apart of about $4 \%$, which compares very favourably with the repeatability of the assessment of adults' $\mathrm{VO}_{2 \mathrm{max}} \cdot{ }^{7}$

Peak $\mathrm{VO}_{2}$ data are available for children as young as 3 years of age, but studies are difficult to interpret and often confounded by small sample sizes, an absence of objective exercise termination criteria, and a tendency to report only mass-related data. The database on 8-16 year-olds is more secure and cross-sectional data indicate an almost linear increase in boys' peak $\mathrm{VO}_{2}\left(\mathrm{~L} \cdot \mathrm{min}^{-1}\right)$ in relation to age. Girls' data demonstrate a similar trend, but with a tendency to level off at about 14 years of age. Longitudinal studies are sparse, but generally reflect the cross-sectional findings. Boys' data show a gradual increase from 8 through and beyond 16 years with the largest annual increases occurring between 13 and 15 years of age. Girls' data are less consistent and peak $\mathrm{VO}_{2}$ appears to progressively rise to 13 years and then level off from about 14 years of age. Boys exhibit higher peak $\mathrm{VO}_{2}$ than girls from prepuberty and over the age range 8-16 years, boys' values increase by about $150 \%$ and girls' by about $80 \%{ }^{3}$

Peak $\mathrm{VO}_{2}$ is highly correlated to body mass and researchers have conventionally 'controlled' for growth by simply dividing peak $\mathrm{VO}_{2}$ by body mass and expressing it as the ratio millilitres of oxygen per kilogramme body 
mass per minute (ie $\mathrm{mL} \cdot \mathrm{kg}^{-1} \cdot \mathrm{min}^{-1}$ ). When peak $\mathrm{VO}_{2}$ is expressed in this manner, a different picture emerges from that apparent when absolute values of peak $\mathrm{VO}_{2}$ (in $\mathrm{L} \cdot \mathrm{min}^{-1}$ ) are used. In most studies boys' mass-related peak $\mathrm{VO}_{2}$ has been reported to remain remarkably stable over the age range 8-16 years with values approximating 48-50 $\mathrm{mL} \cdot \mathrm{kg}^{-1} \cdot \mathrm{min}^{-1}$, whereas girls' values generally fall with increasing age, from about $45-35 \mathrm{~mL} \cdot \mathrm{kg}^{-1} \cdot \mathrm{min}^{-1}$. Boys show higher mass-related peak $\mathrm{VO}_{2}$ than girls throughout childhood and adolescence, with the sex difference reinforced by girls' greater accumulation of body fat during puberty.

Ratio scaling, however, rather than removing the influence of body mass 'over-scales', favours light individuals and penalises heavier ones. This effect can be clearly demonstrated by correlating the ratio scaled variable (peak $\mathrm{VO}_{2}$ in $\mathrm{mL} \cdot \mathrm{kg}^{-1} \cdot \mathrm{min}^{-1}$ ) with the original body mass variable. If the scaling has removed the effect of body mass, the relationship between the two variables should not be significantly different from zero. Numerous studies have shown this not to be the case demonstrating unequivocally the failure of ratio scaling to produce a sizefree variable. ${ }^{3}$

To examine the effect of scaling on the interpretation of peak $\mathrm{VO}_{2}$ during growth and maturation, Welsman et al. ${ }^{8}$ used both ratio and allometric (log-linear analysis of covariance) scaling to remove the effects of body mass from peak $\mathrm{VO}_{2}$ in children, adolescents and adults. In males, the conventional ratio analyses were consistent with the literature showing no significant differences between the age groups. In contrast, the allometric analyses revealed significant, progressive increases in peak $\mathrm{VO}_{2}$ across groups, indicating that relative to body size, males' peak $\mathrm{VO}_{2}$ increased during growth rather than remaining static. Females' ratio scaled peak $\mathrm{VO}_{2}$ showed no change from prepuberty into circumpuberty, but a significant decrease from circumpuberty to adulthood whereas the allometrically scaled data demonstrated that females' peak $\mathrm{VO}_{2}$ significantly increased into puberty with no subsequent decline into young adulthood.

The application of allometry to longitudinal data is complex, but multilevel modelling techniques enable body size, age and sex effects to be partitioned concurrently within an allometric framework. Armstrong \& Welsman ${ }^{9}$ applied multilevel modelling to the interpretation of peak $\mathrm{VO}_{2}$ in 11-17 year-olds and founded the analysis on 388 peak $\mathrm{VO}_{2}$ determinations. They demonstrated a progressive increase in peak $\mathrm{VO}_{2}$ with age in both sexes independent of body mass. The magnitude of the age-related increase was smaller in girls than boys with the difference between the sexes increasing with age. These data challenge the conventional view of peak $\mathrm{VO}_{2}$ during growth, which has been founded on the use of ratio scaling.
As children grow they also mature and the physiological responses of adolescents should be considered in relation to biological as well as chronological age. Several studies have classified maturation according to the indices of pubic hair described by Tanner ${ }^{10}$ and reported peak $\mathrm{VO}_{2}$ in ratio with body mass to be unrelated to maturation in both boys and girls. ${ }^{3}$ However, a study of 17612 year-olds demonstrated that although peak $\mathrm{VO}_{2}$ in ratio with body mass remained unchanged with stage of maturation, when body mass was appropriately controlled using allometry there was a significant, positive effect of maturation on peak $\mathrm{VO}_{2}$ independent of body mass. ${ }^{11}$ Similarly, when stages 2-5 for pubic hair development were introduced into the multilevel model of 11-17 yearolds' peak $\mathrm{VO}_{2}$ described above a significant, positive and incremental effect of stage of maturation on peak $\mathrm{VO}_{2}$ independent of age and body mass, was demonstrated in both sexes. ${ }^{9}$

The data described herein show that the interpretation of young people's aerobic fitness is confounded without appropriate consideration of age, growth and maturation. The use of ratio scaling to accommodate differences in body mass to make comparisons of aerobic fitness within or between studies is widespread, but data expressed in this manner must be treated with caution as the assumption that peak $\mathrm{VO}_{2}$ increases in direct proportion with body mass is not tenable. Inappropriate methods of controlling for body mass have in fact clouded our understanding of aerobic fitness during growth and maturation.

The paper by Rodrigues et al., ${ }^{12}$ published in this issue provides, for the first time, rigorously-determined data on aspects of the aerobic fitness of Brazilian 10-14 year-olds. The valuable study by Rodrigues et al. will initiate further research into an important component of Brazilian youth's health and well-being. The objective of this editorial is to stimulate debate on the interpretation of the data and thereby further the understanding of children and adolescents' aerobic fitness.

\section{References}

1. Astrand PO, Rodahl K. Textbook of work physiology. 2nd ed. New York: McGraw Hill; 1986.

2. Armstrong N, Balding J, Gentle P, Kirby B. Patterns of physical activity among 11 to 16 year old British children. BMJ. 1990;301: 203-5.

3. Armstrong N. Paediatric exercise physiology. Edinburgh: Churchill Livingstone; 2006.

4. Robinson S. Experimental studies of physical fitness in relation to age. Arbeitspyasiologie. 1938;10:251-323.

5. Astrand PO. Experimental studies of physical work capacity in relation to sex and age. Copenhagen: Munksgaard; 1952.

6. Armstrong $\mathrm{N}$, Welsman J, Winsley R. Is peak $\mathrm{VO}_{2}$ a maximal index of children's aerobic fitness? Int J Sports Med. 1996;17: 356-9. 
7. Welsman J, Bywater K, Farr C, Welford D, Armstrong N. Reliability of peak $\mathrm{VO}_{2}$ and maximal cardiac output assessed using thoracic bioimpedance in children. Eur J Appl Physiol. 2005; 94:228-34.

8. Welsman JR, Armstrong N, Nevill AM, Winter EM, Kirby BJ. Scaling peak $\mathrm{VO}_{2}$ for differences in body size. Med Sci Sports Exerc. 1996;28:259-65.

9. Armstrong $\mathrm{N}$, Welsman J. Peak oxygen uptake in relation to growth and maturation. Eur J Appl Physiol. 2001;85:546-51.
10. Tanner JM. Growth at adolescence. 2nd ed. Oxford: Blackwell; 1962.

11. Armstrong N, Welsman JR, Kirby BJ. Peak oxygen uptake and maturation in 12-yr-olds. Med Sci Sports Exerc. 1998; 30:165-9.

12. Rodrigues AN, Perez AJ, Carletti L, Bissoli NS, Abreu GR. Maximum oxygen uptake in adolescents as measured by cardiopulmonary exercise testing: a classification proposal. J Pediatr (Rio J). 2006;82:426-30. 